\title{
Angiogenic factors in human proliferative sickle cell retinopathy
}

\author{
Jingtai Cao, Michaela Kunz Mathews, D Scott McLeod, Carol Merges, \\ Leonard M Hjelmeland, Gerard A Lutty
}

\begin{abstract}
Backgroundlaims-Preretinal neovascular formations called sea fans develop at the border of non-perfused peripheral retina in sickle cell retinopathy. Angiogenic factors which could contribute to their development, however, have not been examined previously. The objective of this study was to determine immunohistochemically if vascular endothelial growth factor (VEGF) or basic fibroblast growth factor (bFGF) were associated with sea fan formations.
\end{abstract}

Methods-Immunohistochemistry on cryosections was used to localise bFGF, VEGF, heparan sulphate proteoglycan, human serum albumin, collagens IV and II, and von Willebrand factor in tissue from five sickle cell and one control subject.

Results-The greatest immunoreactivity for VEGF and bFGF was in the feeder and preretinal vessels of sea fans $(p<0.01)$. The most prominent reaction product was localised to vascular endothelial cells. In retinal vessels, VEGF and bFGF immunoreactivities were greater in sickle cell subjects (both proliferative and nonproliferative) than in the control subject $(p<0.01$ and $p<0.02$ respectively). In the sickle cell retina, no angiogenic factor immunoreactivity was detected in nonperfused periphery and there was no significant difference in bFGF or VEGF immunoreactivity between perfused retina and the border of perfused and non-perfused areas.

Ophthalmological Institute, Johns Hopkins University School of Medicine, Baltimore, MD, USA J Cao

M K Mathews

D S McLeod

C Merges

G A Lutty

School of Medicine, University of California at Davis, Davis, CA, USA L M Hjelmeland

Correspondence to: Gerard A Lutty, PhD, 170 Woods Research Building, Wilmer Ophthalmological Institute, Johns Hopkins Hospital, 600 North Wolfe Street, Baltimore, MD 21287-9115, USA.

Accepted for publication 14 January 1999 mately one in 1000 has SC disease. ${ }^{1}$ The mutations in the $\beta$ globin chain result in haemoglobin which polymerises under acidic or hypoxic conditions. Haemoglobin polymerisation causes erythrocytes (red blood cells, RBCs) to assume abnormal, often sickled shapes. The rigid, abnormally shaped RBCs are believed to cause vaso-occlusions in all organ systems of the sickle cell subject.

In sickle cell retina, vaso-occlusions occur at a young $\operatorname{age}^{23}$ and are first observed in the periphery, resulting in a non-perfused and presumably ischaemic peripheral retina. New blood vessels develop at the border of perfused and non-perfused retina. The elaborate preretinal neovascular structures that form during proliferative sickle cell retinopathy (PSR) are called sea fans because of their resemblance to the marine invertebrate Gorgonia flabellum. These fragile blood vessels can haemorrhage into vitreous and produce traction retinal detachments, the major cause of blindness for sickle cell subjects. ${ }^{4}$ The stimuli for sea fan formation are still unknown.

Two angiogenic growth factors which might initiate formation of sea fans are basic fibroblast growth factor (bFGF) and vascular endothelial growth factor (VEGF). We have observed increased bFGF in retinal blood vessels of an SC sickle cell subject. ${ }^{5}$ We have also previously reported that bFGF immunoreactivity was elevated in diabetic retina. ${ }^{6}$ We and others have also demonstrated that VEGF immunoreactivity is elevated in the early stages of diabetic retinopathy. ${ }^{7-10}$ VEGF has been associated with angiogenic events in other tissues such as tumours. ${ }^{11}$ VEGF is a likely candidate as a stimulus for sea fan formation, because its expression is upregulated by hypoxia. ${ }^{12}{ }^{13}$ VEGF also increases vascular permeability and, clinically, sea fans profusely leak fluorescein dye. ${ }^{14}$

The purposes of this study were to determine if relative levels of VEGF and bFGF immunoreactivity were elevated in both nonproliferative and proliferative sickle cell retina compared with normal retina and to examine if either growth factor was associated with neovascularisation in sickle cell retinopathy. We also wished to determine if changes in localisation of these growth factors were associated with non-perfusion (presumed hypoxia), vascular permeability changes, and extracellular matrix components such as heparan sulphate proteoglycan (HSPG), and collagens type II and type IV.

\section{Methods}

\section{SUBJECTS}

Human postmortem eyes were obtained from the medical eye bank of Maryland (Baltimore, 


\section{Table 1 Subjects}

\begin{tabular}{lllll}
\hline Case & Age/race/sex & $\begin{array}{l}\text { Medical } \\
\text { history }\end{array}$ & Cause of death & PMT/DET \\
\hline 1 & 16/B/F & SC & NA & NA \\
2 & $21 / \mathrm{B} / \mathrm{F}$ & SC & Cardiac arrest & $31 / 4.5$ \\
3 & 28/B/M & SS & Sickle cell disease & $22 / 3$ \\
4 & $40 / \mathrm{B} / \mathrm{F}$ & SS & ASCVD & $24 / 2$ \\
5 & $41 / \mathrm{B} / \mathrm{M}$ & SC & Pulmonary embolism & $24 / 5.5$ \\
6 & $72 / \mathrm{C} / \mathrm{M}$ & Normal & Cardiac arrest & $23.5 / 3$
\end{tabular}

$\mathrm{PMT} / \mathrm{DET}=$ postmortem time/death to enucleation time; $\mathrm{SC}=$ sickle cell disease; $\mathrm{SS}=$ sickle cell anaemia; ASCVD = atherosclerotic cardiovascular disease: $\mathrm{NA}=$ not applicable.

MD, USA) and the National Disease Research Interchange (Philadelphia, PA, USA). One vitrectomy specimen was obtained from the Wilmer Eye Pathology Laboratory at the Johns Hopkins Hospital. Identity of donors remained anonymous and the Johns Hopkins University School of Medicine Human Subjects Board approved the use of human tissue for this study. The cause of death, postmortem time, death to enucleation time, and a brief medical history are given in Table 1. Ocular tissues were fixed and cryopreserved as previously described, ${ }^{15}$ and stored at $-80^{\circ} \mathrm{C}$ until sectioned. Tissue from five sickle cell subjects, four with and one without preretinal neovascularisation and one control subject were analysed. Two sickle cell subjects had sickle cell anaemia (SS) and three had SC disease; the average age of subjects with sickle cell disease was 29.4 years (Table 1 ).

IMMUNOHISTOCHEMISTRY

Immunohistochemistry was performed using serial cryosections on Vectabond (Vector Laboratories) coated slides as previously described. ${ }^{15}$ Briefly, $8 \mu \mathrm{m}$ cryosections were permeabilised with absolute methanol, treated with hydrogen peroxide, and blocked with $2 \%$ serum and $\mathrm{ABC}$ blocking kit (Vector Labs Inc, Burlingame, CA, USA). A series of sections

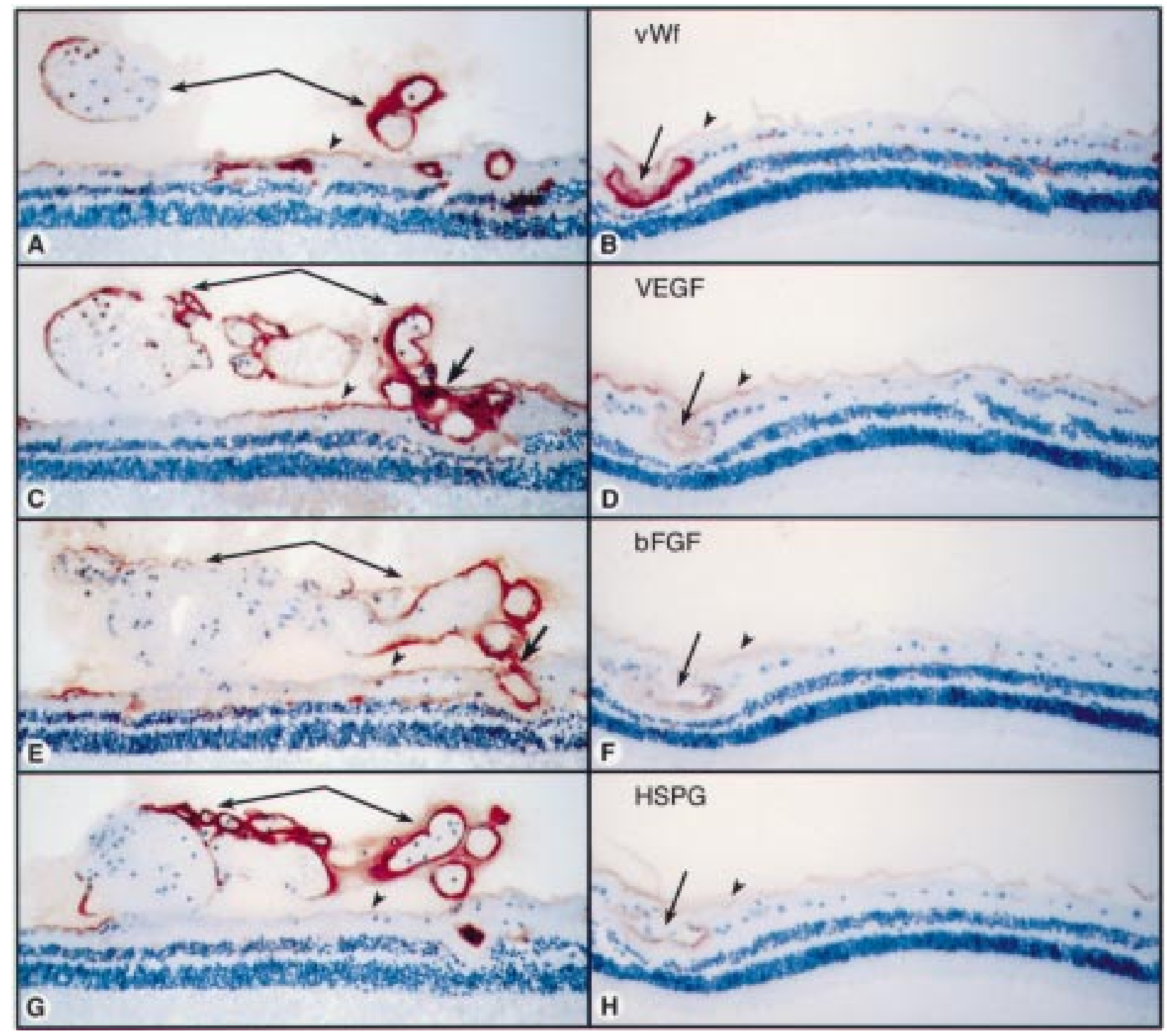

Figure 1 Comparison of 40 year old sickle cell subject (case 4) $(A, C, E, G)$ and 72 year old control subject (case 6) (B, D, F, H). (A) (B) Anti-vWf labels endothelial cells in viable vessels in both subjects. In the sickle cell subject $(A)$ vWf labelling demonstrated that this sea fan formation was composed mostly of large diameter vessels. (C) (D) There was elevated VEGF immunoreactivity in retinal vessels of the sickle cell subject (C) compared with the control subject (D). The greatest VEGF immunoreactivity was in preretinal vessels (arrows) and feeder vessels (bold arrow). (E) (F) bFGF was more prominent in retinal vessels of the sickle cell subject $(E)$ than in the control subject $(F)$. The greatest bFGF was present in the sea fan vessels (arrows) and the feeder vessel (bold arrow). (G) (H) HSPG was present in all viable retinal and preretinal vessels and in the internal limiting membrane (arrowheads) in both subjects but levels were higher in the sickle cell subject $(G)$. 
were incubated overnight at $4^{\circ} \mathrm{C}$ with the following primary antibodies. Rabbit antihuman recombinant VEGF $_{165}$ (A-20, Santa Cruz Biotechnology, Inc) was used at a protein concentration of $0.75 \mu \mathrm{g} / \mathrm{ml}$ after dilution in phosphate buffered saline (PBS) with $1 \%$ BSA. One rabbit anti-human bFGF antibody was generously provided by Ira Herman, $\mathrm{PhD}$, Tufts University, Boston, MS (No 3.1.1) ${ }^{16}$ and the second was provided by Leonard $M$ Hjelmeland, $\mathrm{PhD}$, University of California at
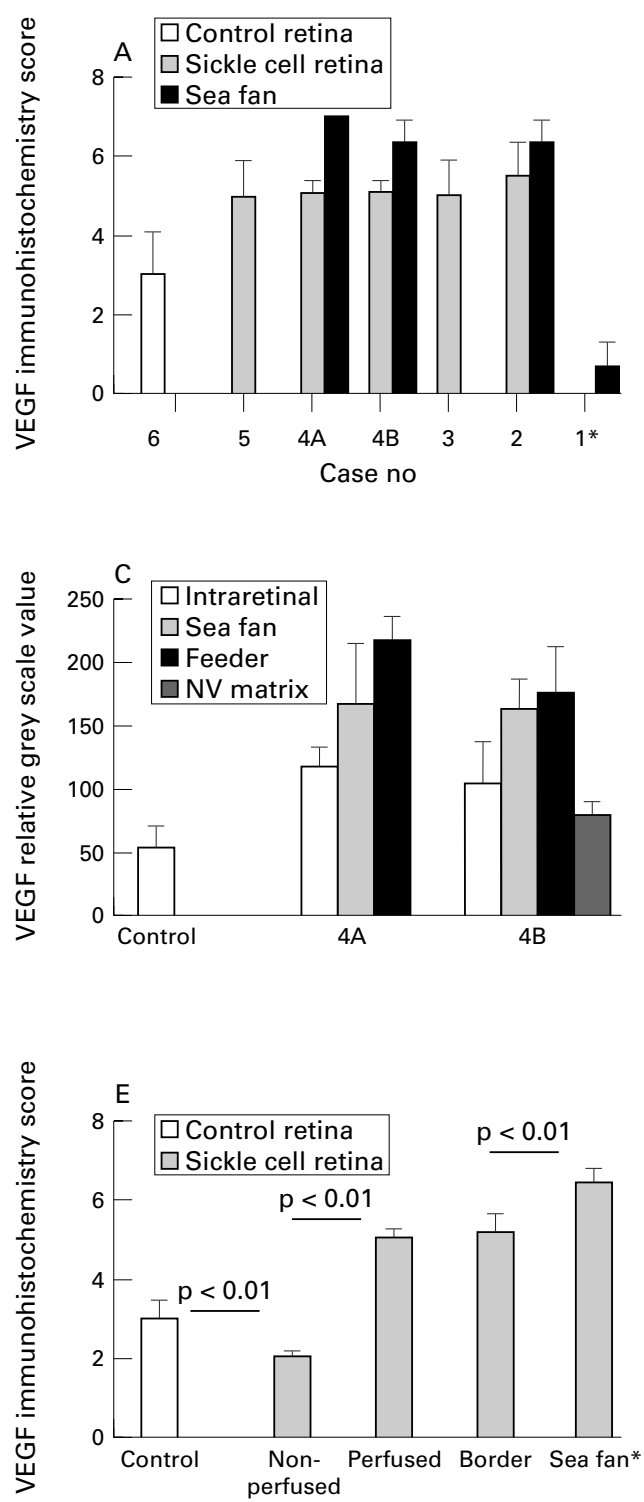

Figure 2 (A) Intensity of VEGF immunoreactivity as scored by three independent observers using a seven point grading system. ${ }^{10}$ The values represent the mean scores from three observers (SD). Retinal vessels in sickle cell subjects had significantly greater VEGF immunoreactivity than retinal vessels in the control subject $(p \leqslant 0.006)$. Three sea fans had greater VEGF immunoreactivity than retinal vessels from the same subjects. However, the vitrectomy sample (case 1) had less immunoreactive VEGF than the control subjects retina $(p=0.001)$. ( ${ }^{\star}$ This preretinal formation had characteristics of a proliferative vitreoretinopathy membrane.) (B) Basic FGF immunoreactivity was comparable (cases 4 and 5) or less (cases 2 and 3) in sickle cell subjects' retinas than in control retina. Basic FGF was significantly elevated in the two sea fans from case 4 compared with any subject's retinal vessels $(p<0.001)$. ( $*$ This preretinal formation had characteristics of a proliferative vitreoretinopathy membrane.) (C) Microdensitometry of VEGF immunoreactivity in two areas from case 4 with sea fans: sample $4 A$ was the area shown in Figure $1 C$; sample $4 B$ was the area shown in Figure $6 . V E G F$ immunoreactivity was greater in the sickle cell retinal vessels than in the control subjects retinal vessels $(p \leqslant 0.007)$. More $V E G F$ was present in the sea fans than in intraretinal vessels in the sickle cell subject $(p<0.04)$. The feeder vessels of sea fans had the greatest immunoreactivity while the matrix had the least. (D) Microdensitometry of bFGF immunoreactivity in two areas from case 4 with sea fans. bFGF immunoreactivity was greater in the retinal vessels of one sickle cell specimen $(4 A$, shown in Fig $1 C)$ than in the control subjects retinal vessels $(p=0.028)$. More bFGF was present in the sea fans than in intraretinal vessels $(p \leqslant 0.022)$. The feeder vessels of sea fans had the greatest immunoreactivity and the difference was significant in the sea fan composed mostly of large vessels (4A). (E) VEGF scores from the control subject (case 6) and a 40 year old sickle cell subject (case 4). The scores for the sickle cell subject represent the mean scores from three observers on two areas with sea fans from case 4 (shown in Fig 1C). 
II (Southern Biotechnology Associates) was diluted to $0.16 \mu \mathrm{g} \mathrm{IgG/ml}$. Mouse anti-human collagen IV (Chemicon International) was provided as ascites fluid and was diluted to 1:60 000. Rabbit anti-von Willebrand factor (vWf, Dako Corporation) was used as a marker for endothelial cells of viable blood vessels at a concentration of $1.16 \mu \mathrm{g} \mathrm{IgG/ml}$. Normal rabbit IgG (Jackson Immuno Research Labs Inc, West Grove, PA, USA) was used as a control for the VEGF antibody at the same IgG concentration.

After washing, sections were incubated for 30 minutes at room temperature with appropriate biotinylated second step antibodies diluted 1:500 (Kirkegaard and Perry, Gaithersburg, MD, USA). Finally, sections were incubated with streptavidin labelled with peroxidase (1:500; Kirkegaard and Perry) and then developed with 3-amino-9-ethylcarbazol (AEC), which yielded a red reaction product. One of the two sections on each slide was counterstained with haematoxylin.

To determine the specificity of VEGF immunolabelling, VEGF antibody was preincubated overnight at $4^{\circ} \mathrm{C}$ with 20 -fold molar excess of VEGF peptide that was used to generate the antibody (Santa Cruz Biotechnology,
Inc) before diluting it to its final concentration. The immunoreactivity from the preincubated antibody was compared with the immunoreactivity from antibody incubated overnight in bovine serum albumin (BSA). The specificity of the bFGF antibodies was determined by preincubating antibody with bFGF bound to Affigel beads for 24 hours at $4^{\circ} \mathrm{C}$ before diluting it to a final concentration.

\section{GRADING SYSTEMS}

Immunoreactivity for each antibody was graded independently by three observers using a seven point grading system. ${ }^{18}{ }^{19}$ The mean score from the three observers was determined and the standard deviation calculated. Microdensitometry analysis of the reaction product was used for comparing reaction product in distinct structures (feeder vessels, sea fans, etc). ${ }^{2021}$ This was accomplished by digitising microscope images of the uncounterstained section on each slide using a Zeiss Photomic II equipped (Oberlachen, Germany) with a Hamamatsu CCD camera (Hamamatsu City, Japan) and a Macintosh IIci computer with a Data Translation frame grabber board (Marlboro, MA, USA) and NIH Image software (version 1.44). Statistical analysis of data was
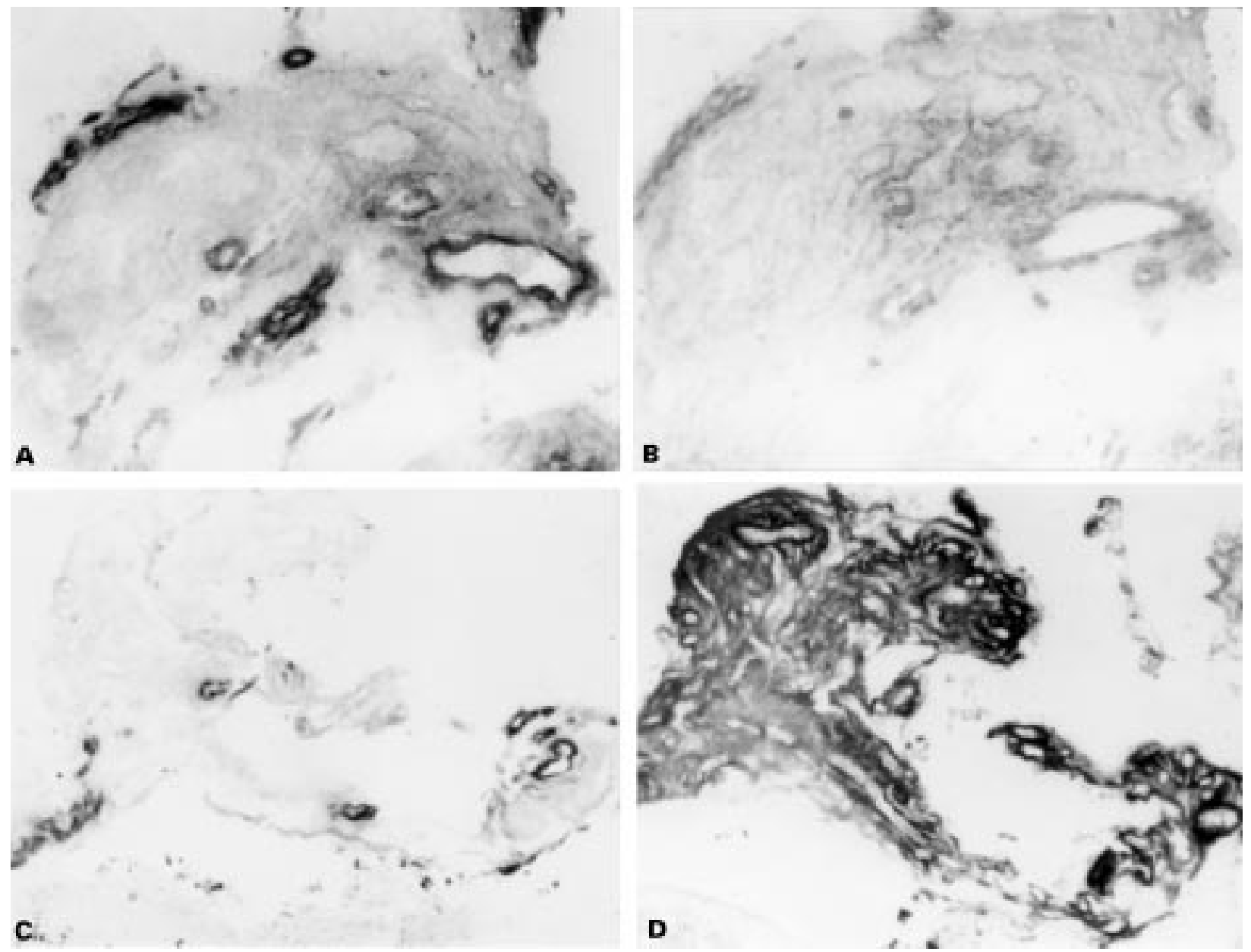

Figure 3 VEGF and HSA localisation in case 2. (A) VEGF localisation in partially infarcted sea fan from case 2 is prominent in vascular endothelial cells and there was less reaction product in the matrix. Antibody was preincubated overnight with BSA before use. (B) Localisation with VEGF antibody that was preincubated overnight with 20-fold molar excess of peptide used to generate VEGF antibody. All vascular labelling was blocked but not all collagenous matrix staining was eliminated. (C) VEGF was present in some active vessels in this partially infarcted sea fan. (D) Serial section showing intense HSA immunoreactivity was associated with blood vessels but was also present in the matrix of this sea fan (original magnification, $A$ and $B \times 196, C$ and $D \times 77$ ). 
performed using the two tailed Student's $t$ test after using an $\mathrm{F}$ test to determine whether equal or unequal variance should be applied. A $p$ value of $\leqslant 0.05$ was considered significant.

\section{Results}

The most prominent VEGF and bFGF immunoreactivities in the control retina were associated with blood vessels (Fig 1). The retinal internal limiting membrane was also positive for VEGF and to a lesser extent for bFGF. VEGF immunoreactivity in retinal vessels of sickle cell subjects (both proliferative and nonproliferative) was greatly increased compared with the control subject (Figs 1 and 2A). Basic FGF immunoreactivity was elevated in three of the five sickle cell retina specimens but the difference compared to the control subject was not significant (Figs 1 and 2B). One of the subjects with lower retinal bFGF levels had non-proliferative retinopathy (case 3). Generally, the VEGF immunoreactivity in sickle cell retina was more prominent than that of bFGF (Fig 1).

The greatest immunoreactivity for VEGF was in viable blood vessels of sea fans with the exception of case 1, a vitrectomy sample from an 16 year old subject (Fig 2A). Blood vessel viability was determined with vWf staining in serial sections. VEGF immunoreactivity was greater in sea fan vessels than in retinal vessels of the same sickle cell subjects (Fig 1 and 2A). VEGF antibody binding in sea fan blood vessels was blocked by preincubation with the peptide used as antigen, but lesser staining of

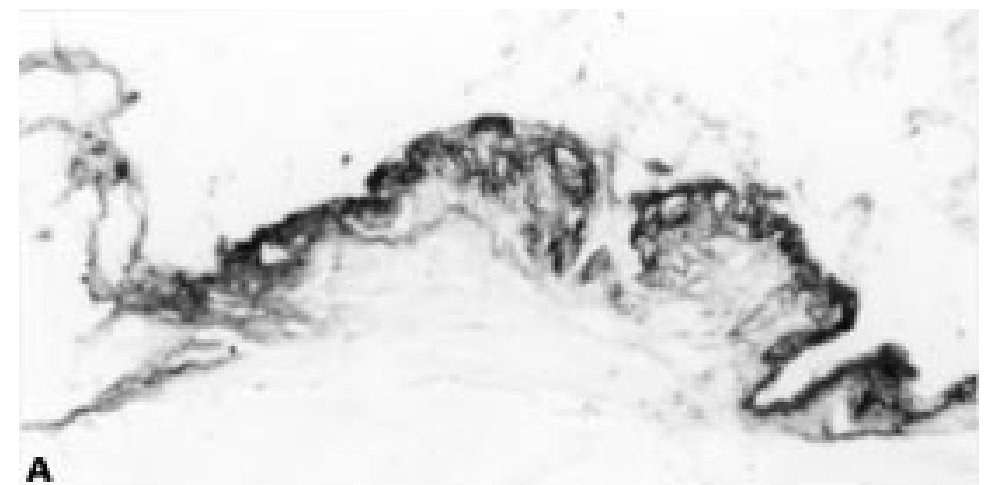

A

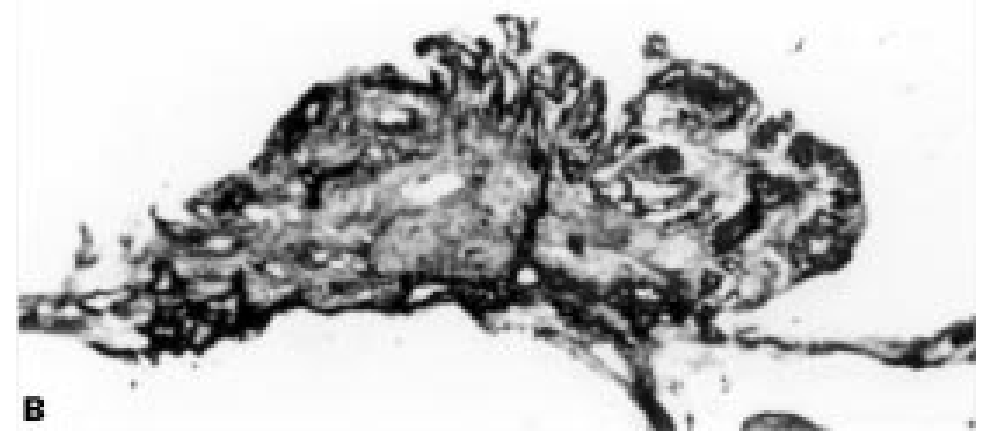

Figure 4 Localisation of collagens II and IV in sea fan from case 2. (A) Collagen type II was increased at the vitreoretinal interface, condensed in vitreous around some sea fans, and present in the periphery of sea fans. (B) Collagen type IV was most prominent in basement membranes of blood vessels and also was distributed throughout the matrix of this sea fan (original magnification $\times 77$ ). the matrix in the sea fan was not eliminated (Fig 3A, B). The greatest observed bFGF immunoreactivity was in two of the sea fan samples (samples $4 \mathrm{~A}$ and $4 \mathrm{~B}$, Fig $2 \mathrm{~B}$ ) which had mostly viable blood vessels (Fig 1). The vascular associated bFGF antibody binding was eliminated by preincubation of the antibody with bFGF Affigel; however, like VEGF, extracellular matrix staining in sea fans remained after preadsorption (data not shown). The sea fan from case 2 was partially infarcted, based on a comparison of vWf and collagen IV immunolabelling, and had less bFGF than the control. This sea fan was composed mostly of collagen IV, which was prominent in blood vessel walls but was also present throughout the sea fan extracellular matrix. Collagen II was confined to the anterior portion of this formation suggesting that vitreous was condensed along the anterior surface of the sea fan (Fig $4 \mathrm{~A}$ and $\mathrm{B})$.

The vitrectomy sample (case 1) had bFGF immunoreactivity comparable with the control subject (Fig 2B), but less VEGF immunoreactivity than the control subject (Fig 2A). Ultrastructural analysis (data not shown) of part of this preretinal membrane demonstrated fibrocytes, pigmented macrophages, blood vessels, and new collagen throughout, which was demonstrated to be type IV collagen in the tissue analysed by immunohistochemistry. These are characteristics of a proliferative vitreoretinopathy (PVR) membrane (Fig 5) and not attributes of a sea fan which has only endothelial cells, pericytes, and smooth muscle cells. ${ }^{22}$ This subject was treated with topical methyl prednisolone and systemic prednisone for 4.5 months before the vitrectomy procedure.

The relation between VEGF immunoreactivity and presumed retinal hypoxia was easily determined in the sickle cell subject because peripheral retina was often non-perfused. Immunohistochemical labelling with vWf (labelled viable blood vessels) and type IV collagen (all blood vessel walls labelled) in serial sections was used to determine the precise location of the border of perfused and peripheral non-perfused retina (arrowheads in Fig 6). We postulated that the border of perfused retina would have more VEGF immunoreactivity considering the relative hypoxia associated with this area. VEGF labelling was performed on a serial section (Fig 6) and then the non-perfused, border area, well perfused central retina, and the sea fan were given separate immunohistochemical scores. The most prominent VEGF immunoreactivity was observed in the sea fans and the least prominent in non-perfused peripheral retina (Fig 2E). Non-perfused peripheral retina had less VEGF immunoreactivity than the control retina $(p<0.01)$. VEGF levels were comparable between the border area of non-perfused retina and central perfused retina in the sickle cell subjects (Fig 2E) and both areas had significantly greater immunoreactivity than the control subject's retina $(\mathrm{p}<0.01)$.

Microdensitometry of reaction product density in non-counterstained sections was used to evaluate discrete areas and individual vessels 
for differences in VEGF immunoreactivity. In the two specimens from case 4 with sea fans, the feeder vessels had the most VEGF immunoreactivity, which was greater than adjacent retinal vessels $(p<0.01)$ (Fig $2 C)$. Feeder vessels also had greater VEGF than the vessels in the sea fans. The perivascular collagenous matrix of the sea fans had less VEGF than vessels in the retina or sea fan, but did have more than measured in the control subject's retinal vessels.

Similar microdensitometric analysis was performed on bFGF immunoreactivity in the same specimens. In the sea fan shown in Figure 1 (specimen 4A in Fig 2D), bFGF immunoreactivity was greatest in the feeder vessel and least in the intraretinal vessels in the same area (Fig 2D). In the sea fan shown in Figure 6, which was mostly capillaries, bFGF levels were comparable in the feeder vessel and in the preretinal vessels. However, there was greater immunoreactivity associated with the sea fan than in adjacent retinal vessels in this sickle cell specimen $(\mathrm{p} \leqslant 0.022)$.

HSPG immunoreactivity was investigated because it is capable of binding heparin binding growth factors such as VEGF and

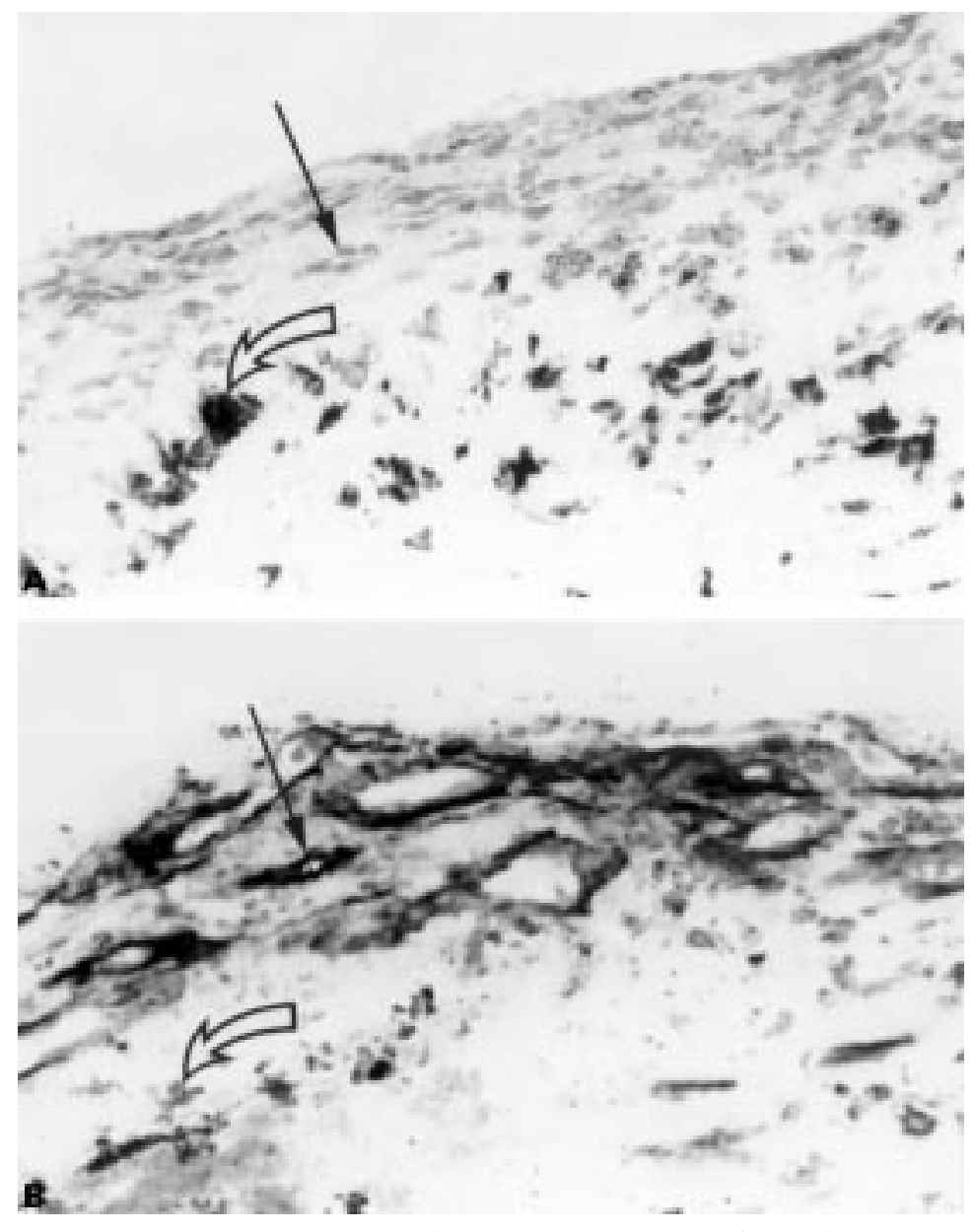

Figure 5 Preretinal formation removed by vitrectomy from case 1. (A) Capillaries were present in the anterior portion of this preretinal formation (straight arrows) but VEGF staining was rather weak. Pigmented cells were also present (curved arrows) suggesting that this structure is similar to a proliferative vitreoretinopathy membrane and not a typical sea fan formation. (B) HSPG labelling in an adjacent area demonstrated that HSPG is associated with the vessels in this structure, so binding sites for VEGF are present (original magnification $\times 196$ ).
bFGF. With the antibody used in this study, HSPG immunoreactivity was observed only in blood vessels with viable endothelial cells (blood vessels positive for vWf) and in the retinal internal limiting membrane (Figs 1 and 6). Using microdensitometry, HSPG immunoreactivity was greater in the retinal vessels of sickle cell retina than in the control retinal vessels and it was greatest in sea fan vessels (data not shown). HSPG immunoreactivity was often colocalised with VEGF (Figs 1 and 6). The only exception was the vitrectomy specimen where HSPG was prominent in vessels and VEGF immunoreactivity was rather weak (Fig 5).

VEGF is known to increase vascular permeability ${ }^{11}$ and vascular permeability can be assessed using immunohistochemistry with an HSA antibody. ${ }^{23}$ HSA leakage was associated with preretinal neovascularisation but HSA immunoreactivity was also observed throughout the sea fan and not just associated with VEGF positive patent vessels (Fig 3C, D). This suggested that permeability in sea fans was greatly increased and might have been chronic. Increased permeability (HSA staining) was not related to the increased VEGF immunoreactivity in retinal vessels of sickle cell subjects nor the control subject.

\section{Discussion}

Our study revealed that two angiogenic factors, VEGF and bFGF, were associated with the sea fan formations in the sickle cell retinopathy. Both growth factors were also elevated in sickle cell retinal vessels in perfused areas compared with the control subject. In a previous case study of an SC subject, we found that bFGF was elevated in retinal vessels, in fibrotic areas of retina associated with a black sunburst lesion, and in choroidal neovascular formations. ${ }^{5}$ In the same subject we found VEGF elevated in retinal vessels compared with control subjects and VEGF was also present in some choroidal neovascular formations. ${ }^{10}$ These observations and studies demonstrating elevated VEGF in subjects with early stages of diabetic retinopathy ${ }^{7-10}$ suggest that both growth factors may be important in ischaemic retinopathies.

In vitro studies suggest that hypoxia induces upregulation of VEGF expression. ${ }^{12}{ }^{13}$ Our study suggests that this may not be true in sickle cell retina. Non-perfused peripheral retina had the least VEGF immunoreactivity in the sickle cell retina and less than the control retina. The area at the border of perfused and non-perfused peripheral retina, which one might assume to be hypoxic, had comparable VEGF immunoreactivity with central well perfused areas of the same retinas. Together, these observations suggest that the VEGF immunoreactivity associated with sea fan formations may not have been produced in a paracrine fashion by adjacent, hypoxic sensory retina, as has been demonstrated by Pe'er et $a l^{24}$ in diabetic retinopathy and Miller et al in a primate venous occlusion model. ${ }^{25}{ }^{26}$ However, the duration of presumed hypoxia in our sickle cell retinas is unknown. It is possible that sen- 
sory retina only produces VEGF for a limited time after becoming hypoxic. The primate venous occlusion model represents an acute event $^{26}$ whereas occlusive events in human sickle cell retinopathy are chronic. ${ }^{4}$

Simorre-Pinatel et al demonstrated that retinal endothelial cells could produce VEGF in an autocrine manner. ${ }^{27}$ Three observations in the current study support autocrine production as a source of both bFGF and VEGF in sickle cell retina. Firstly, the immunoreactivity for these factors was greater in general within the neovascularisation than in adjacent retina and in retinal vessels at the border of perfused retina. Secondly, within the sea fan, the greatest amount of VEGF and bFGF was in the feeder vessels and the least in the matrix. Finally, equivalent retinal vascular immunoreactivity was observed in superior and inferior retina (data not shown), the former being the most common site for sea fan formation and the latter the least common site for sea fan formation. ${ }^{28}$ Therefore, the evidence presented in this study suggests that autocrine production of both growth factors may occur in sickle cell retinopathy.

Alternatively, the increased VEGF and bFGF immunoreactivity observed in sea fans and feeder vessels may simply be growth factor bound to receptors and HSPG. Non-perfused peripheral retina lacked viable endothelial cells and VEGF receptors are expressed primarily on viable vascular endothelial cells and, additionally, the VEGF binding site HSPG was absent from vessels in non-perfused retina. These could be the reasons why the lowest VEGF was in non-perfused peripheral retina. HSPG immunoreactivity was elevated in sickle cell retinal vessels and in blood vessels of sea fans. Although some of the immunoreactivity appeared to be associated with endothelial cells, it is difficult at the light microscopic level to distinguish the endothelial cells from their glycocalyx which contains HSPG. We have previously demonstrated that the majority of the $\mathrm{bFGF}$ in retinal and preretinal vessels in diabetic retinopathy was bound to HSPG. ${ }^{6}$

Paracrine sources of VEGF could be pericytes and smooth muscle cells which both produce VEGF and bFGF when cultured. ${ }^{12}{ }^{29}$ Retinal pigment epithelial cells in vitro produce both bFGF and VEGF. ${ }^{30} 31$ Recent evidence suggests that polymorphonuclear leucocytes (PMNs) also make and secrete VEGF $^{323}$ and we have observed numerous PMNs in blood vessels of sea fans. ${ }^{34}$ In the current study, we observed very low levels of VEGF immunoreactivity in sensory retina of

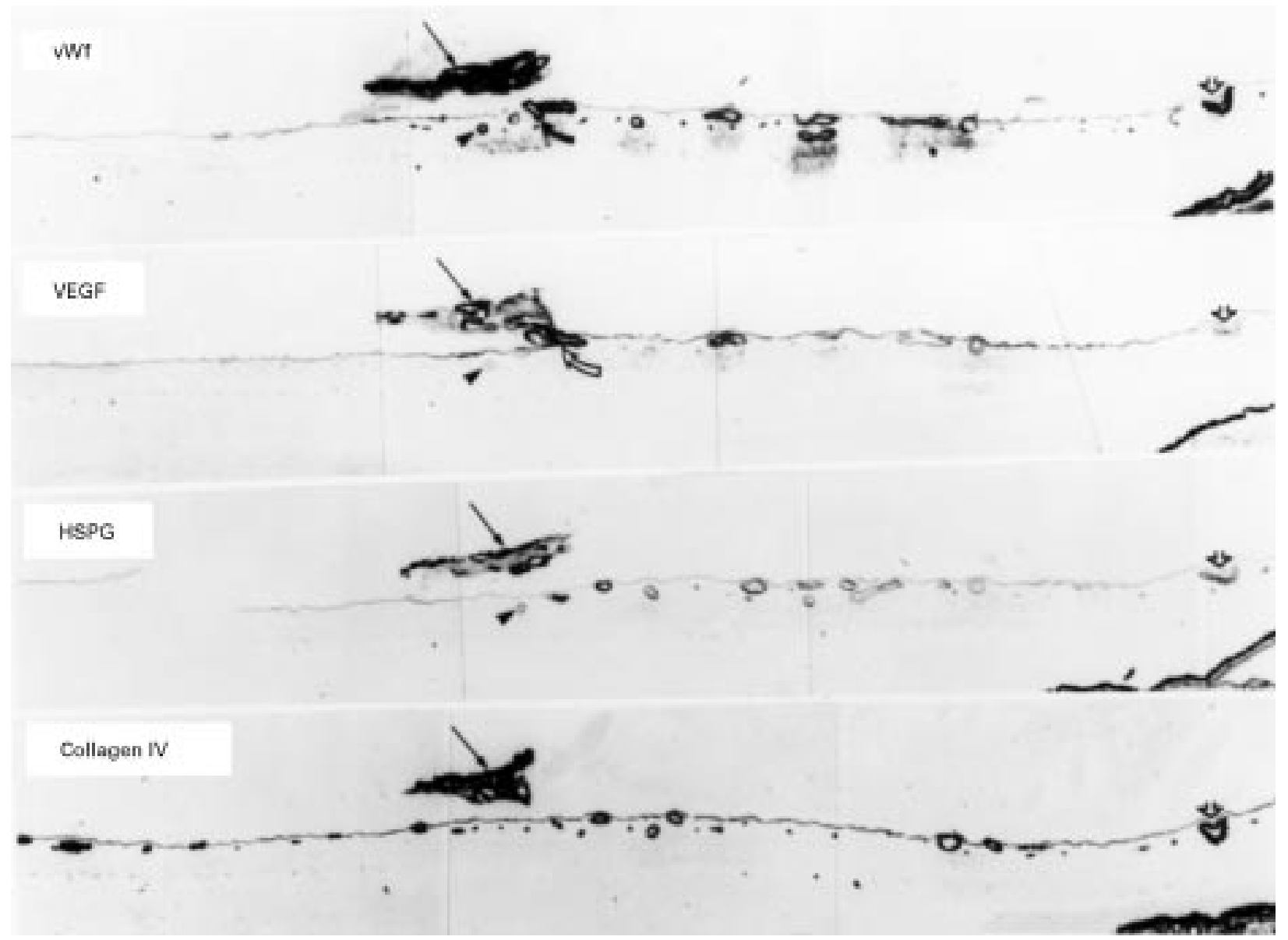

Figure 6 Comparison of non-perfused peripheral retina, the border of perfused and non-perfused retina (arrowheads), and more central perfused retina in case 4. (A) vWF labelling was present in all viable blood vessels but not ghost vessels in peripheral retina (left of arrowhead). $v$ Wf also demonstrated that this sea fan was composed mostly of capillaries. (B) VEGF was most prominent in the sea fan (arrow) and the feeder vessel (curved arrow) and least prominent in non-perfused peripheral retina. Levels were comparable between the border area of perfused and non-perfused retina (arrowhead) and more central perfused retina. (C) HSPG was present in all viable vessels and often colocalised with VEGF (D) Collagen IV was present in all vessels, both perfused and non-perfused, and in the internal limiting membrane. (Same vessel is designated by an open arrow to the right in all serial sections.) 
sickle cell subjects, even at the border of perfused and non-perfused retina, a probable area of hypoxia. As in our studies of diabetic retina, most immunoreactivity was associated with blood vessels. ${ }^{6910}$

In addition to angiogenesis, VEGF is known to increase vascular permeability. ${ }^{1135}$ There was increased vascular permeability in sea fans as demonstrated by greatly increased levels of HSA in these formations and in the surrounding collagenous matrix. However, there was increased VEGF labelling of blood vessels in all areas of the vascularised sickle cell retina compared with the control retina, yet increased HSA immunoreactivity was not present. The increase in HSA in preretinal neovascularisation and not in retinal vessels is analogous to angiographic observations on fluorescein dye leakage in proliferative sickle cell retinopathy. This is in contrast with diabetic retinopathy in which sodium fluorescein leaks from both retinal and preretinal vessels. We have recently observed a good correlation of VEGF with HSA immunoreactivity in early stages of diabetic retinopathy.

The amount of VEGF and bFGF immunoreactivity varied in different sea fans. This appeared to reflect the vascularity of the sea fans. The sea fan with the least bFGF immunoreactivity was partially infarcted (Fig $2 \mathrm{~B}$ and 3 , case 2 ). It had many type IV collagen positive tubes but most of the tubes had reduced HSPG and vWf immunoreactivity. The specimen with the least VEGF immunoreactivity was the vitrectomy sample which had the characteristics of a PVR membrane. Chen et al have recently reported that PVR membranes had substantial VEGF immunoreactivity. ${ }^{36}$ However, the source of the vitrectomy sample used in the current study was a subject who had been treated with topical and systemic steroids before vitrectomy. It is tempting to speculate that steroid treatment might contribute the low levels of VEGF in this particular specimen. Nauck et al have recently reported that steroids could inhibit platelet derived growth factor stimulated production of VEGF by smooth muscle cells. ${ }^{37}$

In summary, this study has demonstrated for the first time that both bFGF and VEGF are associated with sea fan formations in sickle cell retinopathy. The greatest immunoreactive bFGF and VEGF were in preretinal vessels and feeder vessels for the sea fans, which indicates that both factors are likely to promote the growth and expansion of sea fans in sickle cell retinopathy. This study also serves to demonstrate differences in diabetic and sickle cell retinopathies in that in sickle cell retinopathy VEGF was not always associated with increased vascular permeability, whereas it appeared to be in diabetic retinopathy. ${ }^{9}$ Finally, the immunohistochemical data presented suggest that production of VEGF and bFGF in sickle cell retina and preretinal formations may be autocrine.

This study was supported by NIH grants HL45922 (GL), EY06473 (LMH), and EY01765 (Wilmer Institute). G Lutty is an American Heart Association established investigator and the recipient of a Research to Prevent Blindness Lew Wasserman merit award. L Hjelmeland is the recipient of a Research to Prevent Blindness senior scientist award. The authors acknowledge W Richard Green, MD, for his ultrastructural analysis of case 1 and his critical evaluation of this manuscript, Albert $M$ Maguire, MD, for contributing the tissue from case 1, and Ira Herman, PhD, and Alex Ljubimov, PhD, for contributing antibodies for this study.

1 Sickle Cell Disease Guideline Panel. Sickle cell disease: screening, diagnosis, management, and counseling in newborns and infants. Clinical practice guideline no 6. Rockville, MD: Agency for Health Care Policy and Research, Public Health Service, US Department of Health and Human Services, 1993:7-10

2 Talbot JF, Bird AC, Maude GH, et al. Sickle cell retinopathy in Jamaican children: further observations from a cohort study. Br F Ophthalmol 1988;72:727-32.

3 McLeod D, Goldberg M, Lutty G. Dual perspective analysis of vascular formations in sickle cell retinopathy. Arch Ophthalmol 1993;111:1234-45.

4 Lutty G, Goldberg M. Ophthalmologic complications. In: Embury SD, Hebbel RP, Mohandas N, Steinberg MH, eds. Sickle cell disease: basic principles and clinical practice. New York: Raven Press, 1994:703-24.

5 Lutty G, Merges C, Crone S, et al. Immunohistochemical insights into sickle cell retinopathy. Curr Eye Res 1994;13: 125-38.

6 Hanneken A, de Juan E, Lutty G, et al. Altered distribution of basic fibroblast growth factor in diabetic retinopathy. Arch Ophthalmol 1991;109:1005-11.

7 Boulton M, Foreman D, William G, et al. VEGF localisation in diabetic retinopathy. Br $\mathcal{F}$ Ophthalmol 1998;82:561-8.

8 Amin RH, Frank RN, Kennedy A, et al. Vascular endothelial growth factor is present in glial cells of the retina and optic nerve of human subjects with nonproliferative diabetic retinopathy. Invest Ophthalmol Vis Sci 1997;38:36-47.

9 Kunz Mathews M, Merges C, McLeod DS, et al. Vascular endothelial growth factor (VEGF) and vascular permeability changes in human diabetic retinopathy. Invest Ophthalmol Vis Sci 1997;38:2729-41.

10 Lutty GA, McLeod DS, Merges C, et al. Localization of VEGF in human retina and choroid. Arch Ophthalmol 1996;114:971-7.

11 Dvorak HF, Sioussat TM, Brown LF, et al. Distribution of vascular permeability factor (vascular endothelial growth Exp Med 1991;174:1275-8.

12 Aiello LP, Northrup JM, Keyt BA, et al. Hypoxic regulation of vascular endothelial growth factor in retinal cells. Arch Ophthalmol 1995;113:1538-44.

13 Shima DT, Deutsch U, D'Amore P. Hypoxic induction of vascular endothelial growth factor (VEGF) in human epithelial cells is mediated by increases in mRNA stability. FEBS Lett 1995;370:203-8.

14 Goldberg MF. Retinal neovascularization in sickle cell retinopathy. Trans Am Acad Ophthalmol Otolaryngol 1977;83: 409-31.

15 Lutty GA, Merges C, Threlkeld AB, et al. Heterogeneity in localization of isoforms of TGF- $\beta$ in human retina, vitreous, and choroid. Invest Ophthalmol Vis Sci 1993;34: vitreous,

16 Healy AM, Herman IM. Density-dependent accumulation of basic fibroblast growth factor in the subendothelial of basic fibroblast growth factor in
matrix. Eur 7 Cell Biol 1992;59:56-67.

17 Ljubimov AW, Burgeson RE, Butkowski RJ, et al. Basement membrane abnormalities in human eyes with diabetic retinopathy. F Histochem Cytochem 1996;44:1469-79.

18 McLeod D, Lefer D, Merges C, et al. Enhanced expression of intracellular adhesion molecule-1 and P-selectin in the diabetic retina and choroid. Am F Pathol 1995;147:642-53.

19 Page C, Rose M, Yacoub M, et al. Antigenic heterogeneity of vascular endothelium. Am F Pathol 1992;141:673-83.

20 Lutty GA, Merges C, McLeod DS. 5' Nucleotidase and adenosine during retinal vasculogenesis and oxygen(submitted)

21 Taomoto M, McLeod DS, Merges C, et al. Localization of adenosine A2a receptor in retinal development and oxygen-induced retinopathy. Invest Ophthalmol Vis Sci 1999; (submitted).

22 McLeod DS, Merges C, Fukushima A, et al. Histopathological features of neovascularization in sickle cell retinopathy. cal features of neovascularization in

Am f Ophthalmol 1997;124:473-87.
23 Vinores SA, Campochiaro PA, Lee A, et al. Localization of Vinores SA, Campochiaro PA, Lee A, et al. Localization of
blood-retinal barrier breakdown in human pathologic specimens by immunohistochemical staining for albumin. Lab Invest 1990;62:742-50.

24 Pe'er J, Shweiki D, Itin A, et al. Hypoxia-induced expression of vascular endothelial growth factor by retinal cells is a common factor in neovascularizing ocular diseases. Lab Invest 1994;72:638-45.

25 Shima DT, Gougos A, Miller JW, et al. Cloning and mRNA expression of VEGF in ischemic retinas of Macacca fasicularis. Invest Ophthalmol Vis Sci 1996;37:1334-40.

26 Miller JW, Adamis AP, Shima DT, et al. Vascular endothelial growth factor/vascular permeability factor is temporally and spatially correlated with ocular angiogenesis in a primate model. Am f Pathol 1994;145:575-84.

7 Simorre-Pinatel V, Guerrin $M$, Chollet $P$, et al. Vasculotropin-VEGF stimulates retinal capillary endotheDathalmol 994;35:3393-400

28 Goldberg MF. Sickle cell retinopathy. Clinical ophthalmology. Hagerstown, MD: Harper and Row, 1976:1-44. 
29 Stavri GT, Ying H, Zachry I, et al. Hypoxia and plateletderived growth factor-BB synergistically upregulate the expression of vascular endothelial cell growth factor in

vascular smooth muscle cells. FEBS Lett 1995;358:311-15.
Shima DT, Adamis AP, Ferrara N, et al. Hypoxic induction of vascular endothelial growth factors in retinal cells: identifica-
valu tion and characterization of vascular endothelial growth factor (VEGF) as the mitogen. Mol Med 1995;1:182-93.

31 Bost LM, Aotaki-Keen AE, Hjelmeland LM. Coexpression of FGF- 5 and bFGF by retinal pigment epithelium in vitro. Exp Eye Res 1992;55:727-34.

32 Gaudry M, Bregerie O, Andrieu V, et al. Intracellular pool of vascular endothelial growth factor in human neutrophils. Blood 1997;90:4153-61.

33 Taichman NS, Young S, Cruchley AT, et al. Human neutrophils secrete vascular endothelial growth factor. $f$ Leuk Biol 1997;62:397-400.
34 Kunz Mathews M, Cao J, Merges C, et al. Adhesion molecules, neutrophils and imbalance in the fibrinolytic system in sickle cell retinopathy. Invest Ophthalmol Vis Sci 1997;38(suppl):S1117.

35 Shweiki D, Itin A, Soffer D, et al. Vascular endothelial growth factor induced by hypoxia may mediate hypoxiainitiated angiogenesis. Nature 1992;359:843-5.

36 Chen Y-S, Hackett SF, Schoenfeld C-L, et al. Localisation of vascular endothelial growth factor and its receptors to cells of vascular and avascular epiretinal membranes. $\mathrm{Br} \mathcal{F} \mathrm{Oph}$ thalmol 1997;81:919-26.

37 Nauck M, Roth M, Eickelberg O, et al. Induction of vascular endothelial growth factor by platelet-activating factor and platelet-derived growth factor is downregulated by corticosteroids. Am F Respir Cell Mol Biol 1997;16:398406. 